\title{
The health benefits of sweet lupin seed flours and isolated proteins
}

\author{
Anna Arnoldi, * Giovanna Boschin, Chiara Zanoni, and Carmen Lammi \\ Department of Pharmaceutical Sciences, University of Milan, I-20133 Milano, Italy \\ * Corresponding author: Anna Arnoldi, Department of Pharmaceutical Sciences, University of Milan, \\ I-20133 Milano, Italy (e-mail anna.arnoldi@unimi.it)
}

\begin{abstract}
The interest for lupin is continuously growing: one driving force are the numerous studies showing it provides useful health benefits. This review discusses available literature in the area of dyslipidaemia, diabetes, and hypertension prevention, providing hints on the mechanism of action. The addition of lupin protein to the diet of different models of hypercholesterolaemia, such as rat, rabbit, hamster and pig, induce decreases of total and non-HDL cholesterol. The clinical investigations on the cholesterol lowering activity provided controversial results. Those involving hypercholesterolaemic subjects and based on improved lupin foods gave statistically significant total and/or LDL-cholesterol reductions: both protein and fibre are relevant. The moderate hypotensive activity observed in some studies is probably linked to digestion-released ACE-inhibitory peptides. The hypoglycaemic activity, observed in post-prandial studies, is due to gamma-conglutin, a specific protein fraction. All this information suggests that lupin seeds may become a source of ingredients of innovative functional foods.
\end{abstract}

Abbreviations: ACE, angiotensin converting enzyme; Akt, protein kinase B; DBP; diastolic blood pressure; GSK3, glycogen synthase kinase 3; HDL-C, high-density-lipoprotein cholesterol; HMGCoA, 3-hydroxy-3-methylglutaryl coenzyme A; LDL-C, low-density-lipoprotein cholesterol; NL-LUP, narrow-leaf lupin protein isolate; NPS, non-starch polysaccharides; PI3K, phosphatidylinositol 3'-kinase; SBP, systolic blood pressure; SCAP, SREBP-cleavage activating protein; SREBP, sterol regulatory element binding protein; TAG, triacylglycerides; TOC, tocopherol; W-LUP, white lupin protein isolate. 


\section{Introduction}

The interest for sweet lupin seeds is continuously growing stimulated by its flexibility in food preparation as well as by the increasing knowledge of the health benefits it provides. Although different lupin species are used as food, this review will consider only Lupinus albus (white lupin) and Lupinus angustifolius (narrow-leaf lupin), because available data on the biological activity refer only to these species. The use of white lupin as food is consolidated in the Mediterranean area from many centuries, whereas the application in human nutrition of narrow-leaf lupin, which is mainly cultivated in Australia, is much more recent. Both are rich in protein as well as dietary fibre and poor in digestible carbohydrates.

Lupin seeds contain many bioactive components. The protein, which may correspond to $35-40 \%$ of the dry weight (Sujak, Kotlarz, \& Strobel, 2006), is mostly composed of albumins and globulins in an approximate 1 to 9 ratio (Duranti, Consonni, Magni, Sessa, \& Scarafoni, 2008). The most abundant families are known as $\alpha$-conglutin (legumins), $\beta$-conglutin (vicilins), $\gamma$-conglutin, and $\delta$-conglutin (Magni, Scarafoni, Herndl, Sessa, Prinsi, Espen, et al., 2007; Ogura, Ogihara, Sunairi, Takeishi, Aizawa, Olivos-Trujillo, et al., 2014; E. Sirtori, Resta, Brambilla, Zacherl, \& Arnoldi, 2010; Wait, Gianazza, Brambilla, Eberini, Morandi, Arnoldi, et al., 2005). Lupin kernel is also an excellent source of fibre, containing up to $39 \%$ fibre, composed by $75-80 \%$ soluble fibre, $18-25 \%$ insoluble fibre, and 5-9\% hemicellulose (M. Bähr, Fechner, Hasenkopf, Mittermaier, \& Jahreis, 2014). The digestible carbohydrate content is smaller than in most legumes and comprises mostly oligosaccharides, whereas starch is absent or scarce. The fat content is variable, falling in the interval $8-12 \%$ depending on species, with a good presence of $\alpha$-linolenic acid (about 8-10\% of the oil) (Boschin, D'Agostina, Annicchiarico, \& Arnoldi, 2008; Chiofalo, Lo Presti, Chiofalo, \& Gresta, 2012). The unsaponifiable fraction of lupin oil is composed by sterols (mainly $\beta$-sitosterol) and triterpene alcohols (Hamama \& Bhardwaj, 2004; Hudson, Fleetwood, \& Lewis, 1983). Lupin seeds also contain 6-13 mg/100 g of tocopherols, mainly $\gamma$-tocopherol (Boschin \& Arnoldi, 2011; Coisson, Arlorio, Locatelli, Garino, Resta, Sirtori, et al., 2011); 50-230 $\mu \mathrm{g} / 100 \mathrm{~g}$ seed of carotenoids, mainly zeaxantin accompanied by lutein, $\beta$-carotene, and $\alpha$-carotene (Wang, Errington, Yap, Wang, \& Yap, 2008).

Figure 1 shows the main families of polyphenols in lupin seeds. The phenolic acids (in total $43 \mathrm{mg} / \mathrm{kg}$ dry seed in white lupin and $58 \mathrm{mg} / \mathrm{kg}$ in narrow-leaf lupin) are: gallic acid $\mathbf{A}(3.5 \mathrm{mg} / \mathrm{kg}$ in white lupin and $0.6 \mathrm{mg} / \mathrm{kg}$ in narrow-leaf lupin), protocatechuic acid $\mathbf{B}(13.8 \mathrm{mg} / \mathrm{kg}$ in white lupin and 13.1 $\mathrm{mg} / \mathrm{kg}$ in narrow-leaf lupin), p-hydroxybenzoic acid $\mathbf{C}(25.3 \mathrm{mg} / \mathrm{kg}$ in white lupin and $43.2 \mathrm{mg} / \mathrm{kg}$ in narrow-leaf lupin), caffeic acid $\mathbf{D}(0.3 \mathrm{mg} / \mathrm{kg}$ in white lupin and $0.7 \mathrm{mg} / \mathrm{kg}$ in narrow-leaf lupin), and p-coumaric acid E $(0.1 \mathrm{mg} / \mathrm{kg}$ in white lupin and $0.4 \mathrm{mg} / \mathrm{kg}$ in narrow-leaf lupin) (Siger, Czubinski, 
Kachlicki, Dwiecki, Lampart-Szczapa, \& Nogala-Kalucka, 2012). Isoflavones are represented by genistein $\mathbf{F}$ and 2'-hydroxygenistein $\mathbf{G}$, at the concentration of $3-5 \mathrm{mg} / \mathrm{kg}$ and $1-5 \mathrm{mg} / \mathrm{kg}$, respectively (Katagiri, Ibrahim, \& Tahara, 2000; Mellenthin \& Galensa, 1999). The main flavonoids are two Cglucosides of apigenin, i.e. apigenin-6,8-di-C- $\beta$-glucopyranoside $\mathbf{H}(131 \mathrm{mg} / \mathrm{kg}$ in white lupin and $290 \mathrm{mg} / \mathrm{kg}$ in narrow-leaf lupin) and apigenin 7-O- $\beta$-apiofuranosyl-6,8-di-C- $\beta$-glucopyranoside I (258 mg/kg in white lupin and $419 \mathrm{mg} / \mathrm{kg}$ in narrow-leaf lupin) (Siger, Czubinski, Kachlicki, Dwiecki, Lampart-Szczapa, \& Nogala-Kalucka, 2012), which are the most abundant polyphenols in this seed. Compound $\mathbf{I}$ is a rare kind of glycoside, which has been detected mostly in Lupinus (Elbandy \& Rho, 2014; Kamel, 2003).

Different potential health benefits of lupin have been investigated, particularly in the area of dyslipidaemia, hyperglycaemia, and hypertension prevention. In order to select all relevant papers, the systematic Latin names of each species alone and together with one of the following words "clinical trial", "human", "cholesterol”, "glucose", "hypertension", “diabetes", "rat" were used by two persons independently as keywords in Web of Sciences and PubMed. As far as the clinical studies are concerned, this is a systematic review, since all available studies were discussed.

\section{Prevention of dyslipidaemia}

The studies in the area of dyslipidaemia prevention were stimulated by the similarities of the composition of lupin and soybean, which is one of the main functional ingredient for dyslipidaemia prevention (Harland \& Haffner, 2008; Jenkins, Mirrahimi, Srichaikul, Berryman, Wang, Carleton, et al., 2010; C R Sirtori, Eberini, \& Arnoldi, 2007).

\subsection{Animal studies}

Available data on animal studies are summarised in Table 1. Initially, the interest was focused on whole grain. The hypocholesterolaemic property of the heat treated flour of white lupin has been investigated using the hyperlipidaemic rat model (Chango, Bau, Villaume, Schwertz, Nicolas, \& Mejean, 1993). Small but significant decreases of total serum cholesterol and triacylglycerol (TAG) levels were observed in animals treated with lupin (total cholesterol change $-17.8 \%$ ) versus control animals.

Further studies received a great impulse from the approval of the health claim on soy protein and cardiovascular prevention (FDA, 1999) and the demonstration that the protein itself is a main hypocholesterolaemic ingredient in soybean (Consonni, Lovati, Parolari, Manzoni, Morazzoni, Magni, et al., 2011; Duranti, Lovati, Dani, Barbiroli, Scarafoni, Castiglioni, et al., 2004; Lovati, Manzoni, Gianazza, Arnoldi, Kurowska, Carroll, et al., 2000). In a first paper (C. R. Sirtori, Lovati, 
Manzoni, Castiglioni, Duranti, Magni, et al., 2004), rats fed a cholesterol-rich diet containing 20\% casein were treated by gavage for $14 \mathrm{~d}$ with $50 \mathrm{mg} / \mathrm{rat} / \mathrm{d}$ of a lab-prepared total protein extract from white lupin versus the vehicle (control). The lupin-treated rats showed significant decreases in total cholesterol (-22.7\%) and low-density-lipoprotein cholesterol (LDL-C, -30.2\%) versus the control.

A few years later, the possibility of performing biological studies was increased by the availability of large amounts of a purified protein isolate (W-LUP) from white lupin (D'Agostina, Antonioni, Resta, Arnoldi, Bez, Knauf, et al., 2006), containing mostly legumins + vicilins, prepared by the Fraunhofer Institute IVV (Freising, Germany). The cholesterol-lowering activity of this material was successfully assessed in the hypercholesterolaemic rat model: the total cholesterol change was $-11.2 \%$ and LDLC change $-38.7 \%$ (Bettzieche, Brandsch, Weisse, Hirche, Eder, \& Stangl, 2008). The potential antiatherosclerotic activity was tested, instead, in a rabbit model of atherosclerosis (Marchesi, Parolini, Diani, Rigamonti, Cornelli, Arnoldi, et al., 2008). This is an expensive model, very rarely used in dietary studies: small perivascular injuries at both common carotid arteries provoke the development of a focal plaque, whose composition is very similar to the human atherosclerotic one (Chiesa, Di Mario, Colombo, Vignati, Marchesi, Monteggia, et al., 2001). After recovery from surgery, the animals were fed for $90 \mathrm{~d}$ with three different cholesterol-rich diets all containing $20 \%$ protein: the protein sources were casein (control), W-LUP, or a 1:1 mixture of casein + W-LUP. Lower cholesterolaemia was detected in the W-LUP group versus the casein group at 60 and $90 \mathrm{~d}$ of treatment (total cholesterol changes $-40.3 \%$ and $-33.5 \%$, respectively). Cryosection analyses of the carotids indicated a significant reduction in focal lesion progression in the W-LUP versus the casein group $(-37.4 \% ; \mathrm{P}<0.05)$. This important study showed that white lupin exerts a protective activity against the progression of atherosclerosis. Similar changes were observed treating the same model with soybean protein (Castiglioni, Manzoni, D'Uva, Spiezie, Monteggia, Chiesa, et al., 2003).

Finally, the cooked flour and a total protein extract from white lupin have been tested in hamsters again versus casein (Guagagnucci Fontanari, Batistuti, da Cruz, Saldiva, \& Areas, 2012). This model showed that the lupin diet not only induces the expected decrease of total cholesterol $(-16.8 \%$ and $15.3 \%$, respectively) and non-HDL-C (-43.4\% and $-28.6 \%$, respectively), but also reduces the level of liver steatosis (level 1) versus the control diet based on casein (level 4).

The researches on narrow-leaf lupin are more recent. An investigation (Bettzieche, Brandsch, Schmidt, Weisse, Eder, \& Stangl, 2008) compared the hypocholesterolemic activities of the total seed protein extract from the kernel and of a protein isolate containing mostly legumins + vicilins (NLLUP) (again prepared by the Fraunhofer Institute IVV) included at a low percentage in the diet (5\%), demonstrating that NL-LUP is more effective than the total protein extract in lowering cholesterol (total cholesterol changes $+9.7 \%$ and $-5.1 \%$ and VLDL-C + LDL-C changes $-12.7 \%$ and $-15.1 \%$, 
respectively). The study was completed by a molecular investigation, which showed lower hepatic mRNA concentrations of genes involved in fatty acid synthesis and a parallel up-regulation of genes involved in TAG hydrolysis (Bettzieche, Brandsch, Schmidt, Weisse, Eder, \& Stangl, 2008).

Finally, another study on rats showed that a diet containing 20\% NL-LUP markedly lowered total cholesterol (-55.3\%) and LDL-cholesterol levels (-61.2\%) compared to casein, whereas no significant differences were observed for TAG and HDL-C levels (Parolini, Rigamonti, Marchesi, Busnelli, Cinquanta, Manzini, et al., 2012). This study included also some molecular investigations: in particular, the treatment produced significantly higher hepatic mRNA level of SREBP-2, the major transcriptional regulator of intracellular cholesterol levels, and of cholesterol $7 \alpha$-hydroxylase (CYP7A1) level, the rate-limiting enzyme in bile acid biosynthesis (Parolini, et al., 2012).

Another model applied to narrow-leaf lupin was the hyperlipidaemic pig, initially in 2005 (Martins, Riottot, de Abreu, Viegas-Crespo, Lança, Almeida, et al., 2005) and then again in 2014 (Radtke, Geissler, Schutkowski, Brandsch, Kluge, Duranti, et al., 2014). In both researches, significant decreases of total and LDL-cholesterol were observed: in the former the changes in total cholesterol and LDL-C were $-29.2 \%$ and $-37.9 \%$, respectively, in the latter the changes were $-32.6 \%$ and $-28.9 \%$, respectively. The observed reductions of total cholesterol and LDL-C concentrations were explained with an increased faecal cholesterol output (Radtke, et al., 2014).

In conclusion, there are clear experimental evidences suggesting that both species, i.e. white lupin and narrow-leaf lupin, may have potential applications in the area of dyslipidaemia prevention. Unfortunately, the lack of a paper reporting a direct comparison between the two species and the different protocols used in published papers do not permit to sort out which lupin species is the most active.

\subsection{Human studies}

Table 2 shows the specific features of all available clinical trials, whereas Table 3 reports the effects on lipid profile of the subjects involved. These nine studies may be divided in three groups depending on the different lupin ingredients investigated: the first gathers three studies on foods or beverages obtained from whole grain or kernel; the second two studies on lupin fibre; and the last four studies on purified lupin protein. Surprisingly, only the first study was performed on white lupin (Nowicka, Klosiewicz-Latoszek, Sirtori, Arnoldi, \& Naruszewicz, 2006), whereas all the others were on narrowleaf lupin.

Group 1. The first was an uncontrolled study on smokers (Nowicka, Klosiewicz-Latoszek, Sirtori, Arnoldi, \& Naruszewicz, 2006), in which the patients consumed a model drink obtained from white lupin whole grain. Significant decreases in total cholesterol $(-0.42 \mathrm{mmol} / \mathrm{L})$ and LDL-C (-0.32 
$\mathrm{mmol} / \mathrm{L}$ ) were observed in respect to the same values measured during the preceding low lipid diet. This decrease was larger in highly hypercholesterolaemic patients (initial total cholesterol level $>6.2$ $\mathrm{mmol} / \mathrm{L}$ ). A decrease of blood pressure was also observed, which was more evident in hypertensive subjects (see section 4.2).

The others are blind studies on model foods containing whole kernel flour: lupin bread in the former (Hodgson, Lee, Puddey, Sipsas, Ackland, Beilin, et al., 2010) and a portfolio of different lupin foods in the latter (Belski, Mori, Puddey, Sipsas, Woodman, Ackland, et al., 2011). Both studies, involving only subjects with normal or borderline initial cholesterol levels, were essentially inactive on cholesterol. However, decreases of insulin (-16.8\%) and HOMA-IR levels (-32.5\%) were observed in the latter.

Group 2. These studies have investigated purified narrow-leaf lupin fibre, which had been included in different foods (Fechner, Kiehntopf, \& Jahreis, 2014; R. S. Hall, Johnson, Baxter, \& Ball, 2005). Both studies produced significant decreases of total and LDL-C, but the changes were much less favourable in the old study (R. S. Hall, Johnson, Baxter, \& Ball, 2005), where the changes in total cholesterol and LDL-C were $-0.22 \mathrm{mmol} / \mathrm{L}$ and $-0.19 \mathrm{mmol} / \mathrm{L}$, respectively, than in the recent one based on subjects with higher baseline cholesterol levels (Fechner, Kiehntopf, \& Jahreis, 2014), where the changes in total cholesterol and LDL-C were $-0.42 \mathrm{mmol} / \mathrm{L}$ and $-0.33 \mathrm{mmol} / \mathrm{L}$, respectively. In the latter study, a significant decrease of blood pressure was also observed (section 4.2.) and, monitoring the formation of short-chain fatty acids in the intestine, it was observed that lupin fibre significantly increases the excretion of propionate, which may be directly related to the cholesterol-lowering activity (Fechner, Kiehntopf, \& Jahreis, 2014).

Group 3. In all these studies, the tested material was the lupin protein isolate NL-LUP. In two cases, this material was included in dietary bars and the control bars contained casein (C. R. Sirtori, Triolo, Bosisio, Bondioli, Calabresi, De Vergori, et al., 2012; Weisse, Brandsch, Zernsdorf, Nkengfack Nembongwe, Hofmann, Eder, et al., 2010). In the fist study on subjects with a very moderate hypercholesterolaemia (Weisse, et al., 2010), the lupin treatment significantly decreased the lipid parameters compared to the baseline values (total cholesterol and LDL-C changes $-0.50 \mathrm{mmol} / \mathrm{L}$ and $-0.31 \mathrm{mmol} / \mathrm{L}$, respectively), but similar improvements were observed also in the control group (total cholesterol and LDL-C changes $-0.47 \mathrm{mmol} / \mathrm{L}$ and $-0.15 \mathrm{mmol} / \mathrm{L}$, respectively). In the second study on hypercholesterolaemic subjects, which was aimed at investigating the effects of combinations of plant proteins and fibres (C. R. Sirtori, et al., 2012), the lupin bar gave a significant decrease of total cholesterol $(-0.30 \mathrm{mmol} / \mathrm{L})$ versus the control, whereas no changes were observed in the group fed the control bar (casein). LDL-C was, instead, essentially unchanged in both groups.

In the third study, in which NL-LUP was incorporated into a lupin drink, LDL-C was significantly 
lower at the end of the study versus the baseline value, however, this decrease was non-significant versus the control (M Bähr, Fechner, Kramer, Kiehntopf, \& Jahreis, 2013). Better results were obtained in the fourth study of the same group (M. Bähr, Fechner, Kiehntopf, \& Jahreis, 2014), where the patients received a portfolio of different food items containing NL-LUP, very similar to normal foods. LDL-C was significantly lower at the end of the study versus the control, whereas both total cholesterol and LDL-cholesterol were significantly lower at the end of the study versus baseline values. Possibly, the better efficacy of this study may be explained with a relevant improvement of the compliance consequent to the varied portfolio of products that the subjects could easily include in their daily diet.

In conclusion, although the data are still scarce, it seems possible to affirm that either lupin protein or fibre may be potentially useful in the area of dyslipidaemia prevention, especially in hypercholesterolaemic subjects, but that more work is necessary to improve the sensory quality and acceptance of lupin foods. The mechanism of the hypocholesterolemic activity has not been investigated further in these studies, but some explanation may be provided by the results of the experiments described in section 2.3.

The fact that subjects with higher cholesterol are more sensitive to treatment with lupin foods is not unexpected. In particular, a meta-analysis on soybean has shown that the square of the initial serum cholesterol is the main significant predictor of the observed changes of total and LDL cholesterol concentrations observed after soy protein consumption (Anderson, Johnstone, \& Cook-Newell, 1995). The same phenomenon takes place also while consuming other grain legumes (Arnoldi, Zanoni, Lammi, \& Boschin, 2015).

\subsection{In vitro studies}

Very recently, a study on human hepatic HepG2 cells has provided a detailed elucidation of the molecular mechanism by which lupin peptides exert their hypocholesterolaemic activities (Lammi, Zanoni, Scigliuolo, D'Amato, \& Arnoldi, 2014). These experimental evidences (Table 4) indicate that lupin peptides deriving from the hydrolysis of white lupin protein with pepsin (P peptides) and trypsin (T peptides) interfere with the 3-hydroxy-3-methylglutaryl coenzyme A (HMGCoA) reductase activity, up-regulating the LDL receptor (LDLR), and sterol regulatory element binding proteins (SREBP)-2 and increasing the LDL-uptake in HepG2 cells. The transcription of most enzymes involved in cholesterol biosynthesis is regulated by the SREPBs, a family of transcription factors including SREBP-1a, SREBP-1c, and SREBP-2. This last is directly involved in cholesterol metabolism regulation, whereas SREBP-1a and SREBP-1c are involved in fatty acid and TAG metabolism. Usually, both SREBP-1 and SREBP-2 are associated with another endoplasmic 
reticulum membrane protein, the SREBP-cleavage activating protein (SCAP). This complex behaves in two different ways depending on intracellular sterol levels. When there is a decrease or a depletion of intracellular sterols, the SREBP/SCAP complex moves from the endoplasmic reticulum to the Golgi apparatus. When the complex arrives into the Golgi apparatus, SREBP is cleaved by two proteases and the transcription factor domain is activated. In contrast, when the level of intracellular sterols is high, SCAP interacts with insulin-induced genes (Insigs). This interaction hinders the movement of the SREBP/SCAP complex from the endoplasmic reticulum to the Golgi apparatus (Goldstein, DeBose-Boyd, \& Brown, 2006; Sato, 2010).

In this context, although it was generally thought that cholesterol and its oxysterol derivatives were the only effectors regulating the SREBP/SCAP pathway, recent evidence suggests that phosphatidylinositol 3'-kinase (PI3K) / protein kinase B (Akt) activates the SREBPs (Luu, Sharpe, Stevenson, \& Brown, 2012). The molecular mechanism by which Akt activates SREBP-2 is controversial; in fact, Akt might influence SREBP in numerous ways from mRNA transcription to protein degradation (Krycer, Sharpe, Luu, \& Brown, 2010). In particular, recent studies have identified various candidates that could mediate this process, one of which is glycogen synthase kinase 3 (GSK3) that is a direct substrate of Akt. More in details, the Akt-mediated GSK3 inactivation through phosphorylation leads to an indirect stabilisation of the mature form of SREBP-2. In fact, emerging evidences correlate the phosphorylation of SREBP-2 by GSK3 with an increase of the SREBP-2 degradation by ubiquitination and proteasomal activation. For this reason, the GSK3 inactivation, through Akt activation, leads to an increase of SREBP-2 activity (Bengoechea-Alonso \& Ericsson, 2007; Frame \& Cohen, 2001; Punga, Bengoechea-Alonso, \& Ericsson, 2006).

In this context, Lammi and co-workers showed, for the first time, the involvement of Akt/GSK3 $\beta$ activation in LDLR-SREBP-2 pathway regulation after treatment of human hepatic cells with lupin peptides (Lammi et al., 2014). Both $\mathrm{P}$ and T peptides enhanced the LDLR protein levels and induced an increased fluorescent LDL-uptake at HepG2 cells (Table 4), but the LDL uptake was blocked in the presence of $1 \mu \mathrm{M}$ wortmannin (CAS number 19545-26-7), a potent well-known inhibitor of PI3K/Akt (Feldman \& Shokat, 2011). This demonstrated that the inhibition of PI3K/Akt has general effects on cellular lipid homeostasis, although the precise Akt target(s) is(are) not definitely assigned yet. These results prospect that the hypocholesterolaemic activities observed in vivo in animals and humans after lupin protein consumption may be related to some peptides with "statin-like activities" that are released by digestion and absorbed (Carmen Lammi, Zanoni, \& Arnoldi, 2015).

\section{Prevention of hyperglycaemia}


There are some ethnobotanical indications that lupin may be beneficial in diabetes, which have stimulated research also in this area. In post-prandial experiments, healthy volunteers have consumed bread added with narrow-leaf lupin flour (R. Hall, Thomas, \& Johnson, 2005; Keogh, Atkinson, Eisenhauer, Inamdar, \& Brand-Miller, 2011) or kernel fibre (Y P Lee, Mori, Sipsas, Barden, Puddey, Burke, et al., 2006), and the consequent glucose, insulin, and satiety responses have been compared with those induced by regular white bread consumption. In all these papers, significant decrease in the post-prandial levels either of glucose or insulin have been observed versus the control, as well as positive effects on satiety. Also the post-prandial plasma ghrelin concentrations remained lower after consuming lupin fibre enriched bread (Y P Lee, et al., 2006). Another post-prandial study was performed on individuals affected by type 2 diabetes who consumed three beverages containing $50 \mathrm{~g}$ glucose, $50 \mathrm{~g}$ glucose plus narrow-leaf lupin flour, or $50 \mathrm{~g}$ glucose plus soy fibre and protein (Dove, Mori, Chew, Barden, Woodman, Puddey, et al., 2011): the glycaemic response was decreased by lupin, but less efficiently than by soy, whereas lupin improved the insulin response versus the control better than soy (Dove, et al., 2011). The differences in the composition of lupin bread and beverage may possibly explain the different outcomes of these studies.

\subsection{Animal and human studies on $\gamma$-conglutin}

Numerous studies indicate that the main hypoglycaemic component in lupin is $\gamma$-conglutin (Magni, Sessa, Accardo, Vanoni, Morazzoni, Scarafoni, et al., 2004), an unusual basic 7S protein, which is equally soluble in water and salt solutions and corresponds to 4-5\% of the total proteins (Duranti, Consonni, Magni, Sessa, \& Scarafoni, 2008). Each monomer is composed by two disulphide linked subunits, deriving from the post-translational proteolytic cleavage of a pro-polypeptide (Schiarea, Arnoldi, Fanelli, De Combarieu, \& Chiabrando, 2013). This protein is particularly stable to hydrolysis and gives strong interactions with metal ions, especially Zn (Duranti, Scarafoni, Di Cataldo, \& Sessa, 2001). It has been purified from white lupin and thoroughly investigated in vitro and in vivo. A study in acute has shown that, by oral administration, it reduces the plasma glucose levels in rats in a dose dependent manner (Magni, et al., 2004). A three-week treatment with this protein lowered fasting glucose and insulin blood concentrations by about 20-25\% in rats treated with a hyperglycaemic diet (Lovati, Manzoni, Castiglioni, Parolari, Magni, \& Duranti, 2012). The administration of the same protein to a neonatal streptozotocin induced rat model, which mimics type 2 diabetes, has confirmed the hypoglycaemic effects (Vargas-Guerrero, Garcia-Lopez, Martinez-Ayala, Dominguez-Rosales, \& Gurrola-Diaz, 2014).

In order to assess that indeed this protein is more active than other lupin proteins, the hypoglycaemic effect was tested in rats fed a glucose-rich diet in which regular pasta or pastas added with $\gamma$-conglutin 
or with an enriched $\alpha+\beta+\delta$ fraction was included (J. Capraro, Magni, Scarafoni, Caramanico, Rossi, Morlacchini, et al., 2014). The sample including $\gamma$-conglutin was much more efficient than that comprising $\alpha+\beta+\delta$-conglutins in reducing the glycaemic response versus the control.

Finally, $\gamma$-conglutin was also tested in humans, in a placebo-controlled study conducted on 15 healthy volunteers (males and females): the protein was provided as a powder in sachets and the control material was cellulose. A dose of $157 \mathrm{mg}$ (expressed as pure $\gamma$-conglutin) decreased the post-prandial glucose response in a statistically significant way, whereas the overall insulin response was only marginally affected (Bertoglio, Calvo, Hancke, Burgos, Riva, Morazzoni, et al., 2011).

\subsection{Mechanism of action of $\gamma$-conglutin}

The mechanism of action of $\gamma$-conglutin has been investigated using different experimental models. In particular, it has been shown that the intact protein is absorbed by the human intestinal epithelium (Jessica Capraro, Clemente, Rubio, Magni, Scarafoni, \& Duranti, 2011) using two different models. Caco2 were treated with a purified sample of $\gamma$-conglutin and the protein was measured by chemiluminescence-enhanced Western blotting, demonstrating that the intact protein is transferred from the apical to the basolateral side of the intestinal cell monolayer (Jessica Capraro, Clemente, Rubio, Magni, Scarafoni, \& Duranti, 2011). The paper, however, does not clarify the modality of $\gamma$ conglutin transit, i.e. receptor-mediated versus endocytic mechanism. In parallel, in an ex vivo model, the unmodified lupin protein was detected inside the intestinal everted sacs of rat ileum again by using chemiluminescence-enhanced Western blotting for the quantification (Jessica Capraro, Clemente, Rubio, Magni, Scarafoni, \& Duranti, 2011). As a consequence, most molecular investigations have been performed on intact $\gamma$-conglutin.

The mechanism of the antidiabetic activity was investigated in a myocyte model of $\mathrm{C} 2 \mathrm{C} 12$ cells (Terruzzi, Senesi, Magni, Montesano, Scarafoni, Luzi, et al., 2011). This experimentation showed that the glucose-lowering ability of $\gamma$-conglutin is related to the activation of the insulin IRS1/PI3/Akt/p70S6k signalling pathway. This means that this protein is able to modulate the muscle glucose metabolism displaying an insulin-mimetic activity. Moreover, $\gamma$-conglutin can be internalised into hepatic HepG2 cells (Jessica Capraro, Magni, Faoro, Maffi, Scarafoni, Tedeschi, et al., 2013) and, once in the cytoplasm, it is phosphorylated on multiple residues, what probably initiates the activation of the signalling pathway previously mentioned. In this context, it was also shown that $\gamma$ conglutin increases the glucose consumption of HepG2 cells and potentiates the activity of insulin and metformin in cell glucose consumption (Lovati, Manzoni, Castiglioni, Parolari, Magni, \& Duranti, 2012). Finally, an experiment using diabetic rats has shown that $\gamma$-conglutin increases the expression of the Ins-1 gene and the insulin protein content of pancreatic beta cells, possibly 
explaining the effect on hepatic gluconeogenesis (Vargas-Guerrero, Garcia-Lopez, Martinez-Ayala, Dominguez-Rosales, \& Gurrola-Diaz, 2014).

The area of diabetes prevention is certainly one of the most interesting for lupin application. The fact that a single protein seems to be responsible for this activity opens the possibility of its future exploitation in nutraceuticals.

\section{Prevention of hypertension}

Another main area of interest is the prevention of hypertension (W. Y. Huang, S. T. Davidge, \& J. $\mathrm{Wu}, 2013)$.

\subsection{Animal studies}

Only one study (Pilvi, Jauhiainen, Cheng, Mervaala, Vapaatalo, \& Korpela, 2006) has investigated the potential hypotensive effect of the lupin protein isolate W-LUP, by using the Goto-Kakizaki rat model, which develop hypertension when fed a salt-rich diet $(6 \% \mathrm{NaCl})$. The protein sources in the diet were either a W-LUP or a soy protein isolate ( $20 \%$ weight/weight). At the end of the two-week treatment, the systolic blood pressure (SBP) was $18.6 \mathrm{mmHg}$ lower in the lupin group and $12.0 \mathrm{mmHg}$ lower in the soy group than in the control group (casein). The authors explained the attenuation of the hypertension with the improved vascular function observed in the lupin and soy groups in respect to the control group. The difference between soy and lupin is possibly linked with the improved endothelium-dependent vasodilatation observed only with the latter protein (Pilvi, Jauhiainen, Cheng, Mervaala, Vapaatalo, \& Korpela, 2006).

\subsection{Human studies}

Some studies on humans, mainly with other primary end-points, reported also positive effects on blood pressure. In particular, in an uncontrolled study on subjects with moderate hypercholesterolemia and hypertension (Table 2), 42 smokers consumed $35 \mathrm{~g}$ white lupin protein daily in a model beverage (Nowicka, Klosiewicz-Latoszek, Sirtori, Arnoldi, \& Naruszewicz, 2006). Besides positively affecting total and LDL-cholesterol, this treatment significantly reduced also SBP, $-9.5 \mathrm{mmHg}$ after 1 month and $-9.1 \mathrm{mmHg}$ after 3 months, and diastolic blood pressure (DBP), -3.0 $\mathrm{mmHg}$ and $-4.4 \mathrm{mmHg}$, respectively. The changes were more evident in hypertensive subjects (initial $\mathrm{SPB}>140 \mathrm{mmHg}$ ): in this case the changes were SBP $-16.6 \mathrm{mmHg}$ at 1 month and $-22.0 \mathrm{mmHg}$ at 3 months; DPB -1.6 mmHg at 1 month and $-5.0 \mathrm{mmHg}$ at 3 months.

Moreover, two long-term randomized controlled studies showed that the consumption of foods supplemented with narrow-leaf lupin flour produced small but statistically significant decreases in 
blood pressure versus the control foods (Belski, et al., 2011; Ya P. Lee, Mori, Puddey, Sipsas, Ackland, Beilin, et al., 2009). Overweight and obese subjects (88) consumed white wheat bread (control group) or a lupin flour-enriched bread (treated group) for 16 weeks. At the end of this period, the pressure differences in the treatment group versus the control group were $-3.0 \mathrm{mmHg}$ in SBP, $0.6 \mathrm{mmHg}$ in DBP, and $-3.5 \mathrm{mmHg}$ in pulse pressure (Ya P. Lee, et al., 2009). The effect of lupinenriched foods (bread, biscuits and pasta) was evaluated in a double-blind trial during 12 months (Tables 3) (Belski, et al., 2011). Normotensive participants $(n=131)$ were randomly assigned to consume lupin-enriched foods or high carbohydrate control foods. At month 12, the 24-h ambulatory SBP $(-1.3 \mathrm{mmHg})$ and DBP $(-1.0 \mathrm{mmHg})$ of the lupin group were significantly lower than in the control group. The mechanisms behind the observed effects on blood pressure are uncertain. The decrease in blood pressure might possibly result from an improvement in vascular tone mediated by nitric oxide, a potent endothelium-derived relaxing factor, since this effect had been observed in rats (Pilvi et al., 2006). Interestingly, lupin protein is arginine rich (Sujak et al., 2006). Unfortunately, no direct experiment to test this hypothesis was performed in these trials. Finally, significant pressure decreases (-4.13 $\mathrm{mmHg}$ in SBP and $-2.26 \mathrm{mmHg}$ in DBP) were observed in the recent study focused on narrow-leaf lupin fibre (Fechner, Kiehntopf, \& Jahreis, 2014). A significant 0.82-kg reduction of the body weight of the group consuming lupin fibre could partly account for this effect.

\subsection{In vitro studies on ACE-inhibitory peptides}

A possible explanation of the mild hypotensive activity observed either in human or animal studies after lupin consumption is that the proteins are cleaved in the gastrointestinal apparatus generating hypotensive peptides previously encrypted in the parent protein sequence. In fact, it is known (García, Puchalska, Esteve, \& Marina, 2013; Guang \& Phillips, 2009; Puchalska, Marina Alegre, \& García López, 2015) that some food peptides are able to inhibit the activity of ACE (EC 3.4.15.1), which plays an important role in regulating blood pressure in the renin-angiotensin system, because it catalyses the conversion of the biologically inactive angiotensin I to the potent vasoconstrictor angiotensin II and inactivates the potent vasodilator bradykinin (Puchalska, Marina Alegre, \& García López, 2015). Inhibitors bind tightly to the ACE active site competing with angiotensin I for occupancy; as a consequence, ACE cannot convert angiotensin I to angiotensin II. Milk proteins have been initially investigated to identify ACE-inhibiting peptides, but also peptides derived from plants proteins possess this kind of activity (Guang \& Phillips, 2009; Puchalska, Marina Alegre, \& García López, 2015). The investigations on grain legumes were primarily focused on soybean (Margatan, Ruud, Wang, Markowski, \& Ismail, 2013; Tomatsu, Shimakage, Shinbo, Yamada, \& Takahashi, 2013; Wu \& Ding, 2002), and pea (Aluko, 2008; Barbana \& Boye, 2010; Humiski \& Aluko, 2007), 
but other legumes were considered subsequently (Arnoldi, Zanoni, Lammi, \& Boschin, 2015; Boschin, Scigliuolo, Resta, \& Arnoldi, 2014a).

We have recently investigated lupin considering white lupin and narrow-leaf lupin as well as yellow lupin (Lupinus luteus) (Boschin, Scigliuolo, Resta, \& Arnoldi, 2014a, 2014b). Total protein extracts from these seeds were digested with different proteolytic enzymes and the ACE-inhibitory activity was measured obtaining the results shown in Table 5 (Boschin, Scigliuolo, Resta, \& Arnoldi, 2014b). The $\mathrm{IC}_{50}$ values ranged from $136 \pm 4 \mu \mathrm{g} / \mathrm{mL}$ in the case of the yellow lupin sample treated with chymotrypsin to $1053 \pm 78 \mu \mathrm{g} / \mathrm{mL}$ in the case of the white lupin sample treated with umamizyme. In general, the most effective peptide mixtures were obtained with pepsin (mean $\mathrm{IC}_{50}$ value of the three species $186 \pm 10 \mu \mathrm{g} / \mathrm{mL}$ ), followed by pepsin + trypsin (mean $\mathrm{IC}_{50}$ value $198 \pm 16 \mu \mathrm{g} / \mathrm{mL}$ ), chymotrypsin (mean $\mathrm{IC}_{50}$ value $213 \pm 83 \mu \mathrm{g} / \mathrm{mL}$ ), trypsin (mean $\mathrm{IC}_{50}$ value $405 \pm 54 \mu \mathrm{g} / \mathrm{mL}$ ), corolase PP (mean $\mathrm{IC}_{50}$ value $497 \pm 32 \mu \mathrm{g} / \mathrm{mL}$ ), umamizyme (mean $\mathrm{IC}_{50}$ value $865 \pm 230 \mu \mathrm{g} / \mathrm{mL}$ ), and flavourzyme (mean $\mathrm{IC}_{50}$ value $922 \pm 91 \mu \mathrm{g} / \mathrm{mL}$ ). Interestingly, the hydrolysates of the three species obtained with the same enzyme showed equivalent activities (Table 5).

With the objective of sorting out the effective components, some purified protein fractions or protein isolates from white lupin prepared in a pilot plant were compared (Boschin, Scigliuolo, Resta, \& Arnoldi, 2014a), after hydrolysis with pepsin (Boschin, Scigliuolo, Resta, \& Arnoldi, 2014b). The most active lupin protein component is the vicilins + legumins fraction, since both the hydrolysates from the lab sample ( $\mathrm{IC}_{50}$ value $138 \pm 5 \mu \mathrm{g} / \mathrm{mL}$ ) and the pilot-scale preparation W-LUP (IC 50 value $142 \pm 4 \mu \mathrm{g} / \mathrm{mL})$ were more active than the respective total protein extracts $(268 \pm 11.9 \mu \mathrm{g} / \mathrm{mL}$ and $165 \pm 3 \mu \mathrm{g} / \mathrm{mL}$, respectively). On the contrary, both $\gamma$-conglutin and $\delta$-conglutin hydrolysates were completely inactive.

Although there are not yet direct experimental evidences, on the basis of these results, the hypothesis that the formation of ACE-inhibitory peptides may explain at least in part the hypotensive effects observed in vivo appears, therefore, feasible.

A completely unexplored area is the possible role of polyphenols on the hypotensive effects exerted by lupin foods: in fact, numerous polyphenols have major role in the hypotensive activity of different plant extracts, such as cocoa, tea, grain, vegetables, fruits (Fernandez-Arroyo, Camps, Menendez, \& Joven, 2015; Galleano, Pechanova, \& Fraga, 2010; W. Y. Huang, S. T. Davidge, \& J. P. Wu, 2013). In particular, apigenin has been demonstrated to be an inhibitor of angiotensin I converting enzyme (ACE) either in vitro (Ayouo \& Melzig, 2006) or in silico (Hafeez et al., 2014).

\section{Final considerations}


Available experimental evidences, both in animals and humans, indicate that lupin may provide some useful health benefits in the area of hypercholesterolaemia, diabetes, and hypertension prevention. The observed effects probably derive from the synergistic combination of the activities of many seed components. In particular, human studies indicate that either the fibre (Fechner, Kiehntopf, \& Jahreis, 2014; R. S. Hall, Johnson, Baxter, \& Ball, 2005) or the protein (M. Bähr, Fechner, Kiehntopf, \& Jahreis, 2014; C. R. Sirtori, et al., 2012) are hypocholesterolemic components. The fibre activity seems to depend on effects at intestine level, in particular on cholesterol and cholic acid binding and on the formation of short-chain fatty acids (Fechner, Kiehntopf, \& Jahreis, 2014), with mechanisms which are common to other dietary fibres (Aleixandre \& Miguel, 2008; Delzenne \& Cani, 2011). The hypoglycaemic activity seems to be related to a specific protein i.e. $\gamma$-conglutin, possibly absorbed intact from the intestine (Jessica Capraro, Clemente, Rubio, Magni, Scarafoni, \& Duranti, 2011). The explanation of the hypocholesterolemic and hypotensive activities of the protein, instead, seems to depend on specific peptides (Boschin, Scigliuolo, Resta, \& Arnoldi, 2014a, 2014b; C. Lammi, Zanoni, Scigliuolo, D'Amato, \& Arnoldi, 2014), which originally encrypted in the protein sequences are released during digestion. Of course, there is still an open question whether these peptides are really absorbed in vivo. Although the experimental evidences are still scarce, a very recent paper on Caco 2 cells has demonstrated that peptides deriving from the hydrolysis of soy proteins may be easily absorbed and transferred in the basolateral compartment (Amigo-Benavent, Clemente, Caira, Stiuso, Ferranti, \& del Castillo, 2014). This makes feasible the absorption of lupin peptides from the gut.

In the meanwhile, only a limited attention has been paid to the possible roles of other components. In particular, surprisingly, the health benefits provided by lupin polyphenols have been rarely investigated, although these phytochemicals are main bioactive food components, providing numerous health benefits. In particular, they are strong antioxidants, useful for preventing lipid oxidation and atherosclerosis formation, and efficient ACE-inhibitors (Sato, Mukai, Yamate, Kato, Kurasaki, Hatai, et al., 2008; Shahidi \& Chandrasekara, 2013; Taku, Umegaki, Sato, Taki, Endoh, \& Watanabe, 2007). As already indicated in the introduction, the two most abundant polyphenols in lupin are apigenin-6,8-di-C- $\beta$-glucopyranoside $\mathbf{H}$ and apigenin 7 -O- $\beta$-apiofuranosyl-6,8-di-C- $\beta$ glucopyranoside I. The latter is typical of the genus Lupinus, whereas the former has been identified in phytocomplexes of other plants whose health benefits have been investigated: for example those of Potentilla discolor (Song, Huang, Rong, Zhou, Peng, Yu, et al., 2012) and Ocimum gratissimum (Casanova, da Silva, Sola-Penna, Camargo, Celestrini, Tinoco, et al., 2014) are hypoglycaemic and that of Aspalathus linearis (Beltran-Debon, Rull, Rodriguez-Sanabria, Iswaldi, Herranz-Lopez, Aragones, et al., 2011) is hypocholesterolaemic. 
It is now useful to observe that most of the experimental and clinical studies discussed in this review have been performed on purified proteins or protein isolates. Considering that polyphenols may strongly interact with proteins either by covalent or non-covalent binding, a still open issue is the possible role of polyphenols in the observed effects. Unfortunately, literature does not report any analytical data on the concentration of polyphenols in the materials used in these clinical studies, although a recent paper has shown that lupin seed globulins form stable complexes with flavonoids and in particular with apigenin C-glucosides $\mathbf{H}$ and $\mathbf{I}$ (Czubinski, Dwiecki, Siger, Kachlicki, Neunert, Lampart-Szczapa, et al., 2012). In fact, a study has shown that the digestion of the lupin protein with pepsin releases these apigenin derivatives that may be easily identified by mass spectrometry (Czubinski, et al., 2012). This important issue would certainly deserve a detailed investigation. Another main open question is the actual bioavailability of these C-glucosides, since data are very incomplete (Escudero-Lopez, Calani, Fernandez-Pachon, Ortega, Brighenti, Crozier, et al., 2014; Stalmach, Mullen, Pecorari, Serafini, \& Crozier, 2009).

Other important properties of lupin underlined by recent literature, such as the antioxidant activity (Siger et al., 2012) and the anti-inflammatory activity (Millan-Linares, Bermudez, Yust, Millan, \& Pedroche, 2014), should depend principally on phenolic acids and these flavonoids. These activities confirms the multifunctional features of lupin and provide further hints on the possible role of lupin products among functional foods for cardiovascular disease protection (Braithwaite, Tyagi, Tomar, Kumar, Choonara, \& Pillay, 2014; Chen, Ma, Liang, Peng, \& Zuo, 2011; Scicchitano, Cameli, Maiello, Modesti, Muiesan, Novo, et al., 2014).

Acknowledgement. Researches funded in part by the European Union Seventh Framework Programme (FP7/2007-2013), under grant agreement n. 285819. We are indebted to Regione Lombardia and HPF-Nutraceutics SRL (Milan, Italy) for the partial funding of a postdoc fellowship to $\mathrm{CZ}$ (Dote Ricerca Post-doc Fellowships).

Conflict of interest. The Authors do not declare any conflict of interest. 


\section{REFERENCES}

Aleixandre, A., \& Miguel, M. (2008). Dietary fiber in the prevention and treatment of metabolic syndrome: a review. Crit Rev Food Sci Nutr, 48(10), 905-912.

Aluko, R. E. (2008). Determination of nutritional and bioactive properties of peptides in enzymatic pea, chickpea, and mung bean protein hydrolysates. J AOAC Int, 91, 947-956.

Amigo-Benavent, M., Clemente, A., Caira, S., Stiuso, P., Ferranti, P., \& del Castillo, M. D. (2014). Use of phytochemomics to evaluate the bioavailability and bioactivity of antioxidant peptides of soybean $\beta$-conglycinin. Electrophoresis, 35(11), 1582-1589.

Anderson, J. W., Johnstone, B. M., \& Cook-Newell, M. E. (1995). Meta-analysis of the effects of soy protein intake on serum lipids. N Engl J Med, 333(5), 276-282.

Arnoldi, A., Zanoni, C., Lammi, C., \& Boschin, G. (2015). The role of grain legumes in the prevention of hypercholesterolemia and hypertension. Critic Rev Plant Sci, 34(1-3), 144168.

Barbana, C., \& Boye, J. I. (2010). Angiotensin I-converting enzyme inhibitory activity of chickpea and pea protein hydrolysates. Food Res. Int., 43, 1642-1649.

Belski, R., Mori, T. A., Puddey, I. B., Sipsas, S., Woodman, R. J., Ackland, T. R., Beilin, L. J., Dove, E. R., Carlyon, N. B., Jayaseena, V., \& Hodgson, J. M. (2011). Effects of lupinenriched foods on body composition and cardiovascular disease risk factors: a 12-month randomized controlled weight loss trial. Int. J. Obes., 35(6), 810-819.

Beltran-Debon, R., Rull, A., Rodriguez-Sanabria, F., Iswaldi, I., Herranz-Lopez, M., Aragones, G., Camps, J., Alonso-Villaverde, C., Menendez, J. A., Micol, V., Segura-Carretero, A., \& Joven, J. (2011). Continuous administration of polyphenols from aqueous rooibos (Aspalathus linearis) extract ameliorates dietary-induced metabolic disturbances in hyperlipidemic mice. Phytomedicine, 18(5), 414-424.

Bertoglio, J. C., Calvo, M. A., Hancke, J. L., Burgos, R. A., Riva, A., Morazzoni, P., Ponzone, C., Magni, C., \& Duranti, M. (2011). Hypoglycemic effect of lupin seed $\gamma$-conglutin in experimental animals and healthy human subjects. Fitoterapia, 82(7), 933-938. 
Bettzieche, A., Brandsch, C., Schmidt, M., Weisse, K., Eder, K., \& Stangl, G. (2008). Differing effect of protein isolates from different cultivars of blue lupin on plasma lipoproteins of hypercholesterolemic rats. Biosci Biotechnol Biochem, 72(12), 3114-3121.

Bettzieche, A., Brandsch, C., Weisse, K., Hirche, F., Eder, K., \& Stangl, G. (2008). Lupin protein influences the expression of hepatic genes involved in fatty acid synthesis and triacylglycerol hydrolysis of adult rats. Br J Nutr, 99(5), 952-962.

Boschin, G., \& Arnoldi, A. (2011). Legumes are valuable sources of tocopherols. Food Chem, 127(3), 1199-1203.

Boschin, G., D'Agostina, A., Annicchiarico, P., \& Arnoldi, A. (2008). Effect of genotype and environment on fatty acid composition of Lupinus albus L. seed. Food Chemistry, 108(2), 600-606.

Boschin, G., Scigliuolo, G. M., Resta, D., \& Arnoldi, A. (2014a). ACE-inhibitory activity of enzymatic protein hydrolysates from lupin and other legumes. Food Chem, 145, 34-40.

Boschin, G., Scigliuolo, G. M., Resta, D., \& Arnoldi, A. (2014b). Optimization of the enzymatic hydrolysis of lupin (Lupinus) proteins for producing ACE-inhibitory peptides. J Agric Food Chem, 62(8), 1846-1851.

Braithwaite, M. C., Tyagi, C., Tomar, L. K., Kumar, P., Choonara, Y. E., \& Pillay, V. (2014). Nutraceutical-based therapeutics and formulation strategies augmenting their efficiency to complement modern medicine: An overview. Journal of Functional Foods, 6, 82-99.

Bähr, M., Fechner, A., Hasenkopf, K., Mittermaier, S., \& Jahreis, G. (2014). Chemical composition of dehulled seeds of selected lupin cultivars in comparison to pea and soya bean. Lwt-Food Sci Technol, 59(1), 587-590.

Bähr, M., Fechner, A., Kiehntopf, M., \& Jahreis, G. (2014). Consuming a mixed diet enriched with lupin protein beneficially affects plasma lipids in hypercholesterolemic subjects: A randomized controlled trial. Clin Nutr, http://dx.doi.org/10.1016/j.clnu.2014.1003.1008.

Bähr, M., Fechner, A., Kramer, J., Kiehntopf, M., \& Jahreis, G. (2013). Lupin protein positively affects plasma LDL cholesterol and LDL:HDL cholesterol ratio in hypercholesterolemic adults after four weeks of supplementation: a randomized, controlled crossover study. Nutr $J, 12,107$. 
Capraro, J., Clemente, A., Rubio, L. A., Magni, C., Scarafoni, A., \& Duranti, M. (2011).

Assessment of the lupin seed glucose-lowering protein intestinal absorption by using in vitro and ex vivo models. Food Chem, 125(4), 1279-1283.

Capraro, J., Magni, C., Faoro, F., Maffi, D., Scarafoni, A., Tedeschi, G., Maffioli, E., Parolari, A., Manzoni, C., Lovati, M. R., \& Duranti, M. (2013). Internalisation and multiple phosphorylation of gamma-Conglutin, the lupin seed glycaemia-lowering protein, in HepG2 cells. Biochem Biophys Res Comm, 437(4), 648-652.

Capraro, J., Magni, C., Scarafoni, A., Caramanico, R., Rossi, F., Morlacchini, M., \& Duranti, M. (2014). Pasta supplemented with isolated lupin protein fractions reduces body weight gain and food intake of rats and decreases plasma glucose concentration upon glucose overload trial. Food \& Funct, 5(2), 375-380.

Casanova, L. M., da Silva, D., Sola-Penna, M., Camargo, L. M. D., Celestrini, D. D., Tinoco, L. W., \& Costa, S. S. (2014). Identification of chicoric acid as a hypoglycemic agent from Ocimum gratissimum leaf extract in a biomonitoring in vivo study. Fitoterapia, 93, 132141.

Castiglioni, S., Manzoni, C., D'Uva, A., Spiezie, R., Monteggia, E., Chiesa, G., Sirtori, C. R., \& Lovati, M. R. (2003). Soy proteins reduce progression of a focal lesion and lipoprotein oxidiability in rabbits fed a cholesterol-rich diet. Atherosclerosis, 171(2), 163-170.

Chango, A., Bau, H., Villaume, C., Schwertz, A., Nicolas, J., \& Mejean, L. (1993). [Effects of treatments (heat and fermentation by Rhizopus oligosporus sp-T3) of sweet white lupin seeds on certain factors of its nutritional use]. Reprod Nutr Dev, 33(2), 89-98.

Chen, Z.-Y., Ma, K. Y., Liang, Y., Peng, C., \& Zuo, Y. (2011). Role and classification of cholesterol-lowering functional foods. Journal of Functional Foods, 3(2), 61-69.

Chiesa, G., Di Mario, C., Colombo, N., Vignati, L., Marchesi, M., Monteggia, E., Parolini, C., Lorenzon, P., Laucello, M., Lorusso, V., Adamian, M., Franceschini, G., Newton, R., \& Sirtori, C. R. (2001). Development of a lipid-rich, soft plaque in rabbits, monitored by histology and intravascular ultrasound. Atherosclerosis, 156(2), 277-287.

Chiofalo, B., Lo Presti, V., Chiofalo, V., \& Gresta, F. (2012). The productive traits, fatty acid profile and nutritional indices of three lupin (Lupinus spp.) species cultivated in a Mediterranean environment for the livestock. Anim Feed Sci Technol, 171(2-4), 230-239. 
Coisson, J. D., Arlorio, M., Locatelli, M., Garino, C., Resta, D., Sirtori, E., Arnoldi, A., \& Boschin, G. (2011). The artificial intelligence-based chemometrical characterisation of genotype/chemotype of Lupinus albus and Lupinus angustifolius permits their identification and potentially their traceability. Food Chem, 129(4), 1806-1812.

Consonni, A., Lovati, M. R., Parolari, A., Manzoni, C., Morazzoni, P., Magni, C., \& Duranti, M. (2011). Heterologous expression and purification of the soybean 7S globulin $\alpha^{\prime}$ subunit extension region: in vitro evidence of its involvement in cell cholesterol homeostasis. Protein Expr Purif, 80(1), 125-129.

Czubinski, J., Dwiecki, K., Siger, A., Kachlicki, P., Neunert, G., Lampart-Szczapa, E., \& NogalaKalucka, M. (2012). Release of Flavonoids from Lupin Globulin Proteins during Digestion in a Model System. Journal of Agricultural and Food Chemistry, 60(7), 1830-1836.

D'Agostina, A., Antonioni, C., Resta, D., Arnoldi, A., Bez, J., Knauf, U., \& Waesche, A. (2006). Optimization of a pilot-scale process for producing lupin protein isolates with valuable technological properties and minimum thermal damage. J Agric Food Chem, 54(1), 92-98.

Delzenne, N. M., \& Cani, P. D. (2011). Interaction between obesity and the gut microbiota: relevance in nutrition. Annu Rev Nutr, 31, 15-31.

Dove, E. R., Mori, T. A., Chew, G. T., Barden, A. E., Woodman, R. J., Puddey, I. B., Sipsas, S., \& Hodgson, J. M. (2011). Lupin and soya reduce glycaemia acutely in type 2 diabetes. $B r J$ Nutr, 106(7), 1045-1051.

Duranti, M., Consonni, A., Magni, C., Sessa, F., \& Scarafoni, A. (2008). The major proteins of lupin seed: characterisation and molecular properties for use as functional and nutraceutical ingredients. Trends Food Sci Technol, 19(12), 624-633.

Duranti, M., Lovati, M. R., Dani, V., Barbiroli, A., Scarafoni, A., Castiglioni, S., Ponzone, C., \& Morazzoni, P. (2004). The alpha' subunit from soybean 7S globulin lowers plasma lipids and upregulates liver beta-VLDL receptors in rats fed a hypercholesterolemic diet. $J$ Nutr, 134(6), 1334-1339.

Duranti, M., Scarafoni, A., Di Cataldo, A., \& Sessa, F. (2001). Interaction of metal ions with lupin seed conglutin gamma. Phytochemistry, 56(6), 529-533. 
Elbandy, M., \& Rho, J. R. (2014). New flavone-di-C-glycosides from the seeds of Egyptian lupin (Lupinus termis). Phytochemistry Letters, 9, 127-131.

Escudero-Lopez, B., Calani, L., Fernandez-Pachon, M. S., Ortega, A., Brighenti, F., Crozier, A., \& Del Rio, D. (2014). Absorption, metabolism, and excretion of fermented orange juice (poly)phenols in rats. Biofactors, 40(3), 327-335.

FDA. (1999). Food labeling health claims: soybean protein and coronary heart disease. Final rule. Federal Register. 64, 57699- 57733.

Fechner, A., Kiehntopf, M., \& Jahreis, G. (2014). The formation of short-chain fatty acids is positively associated with the blood lipid-lowering effect of lupin kernel fiber in moderately hypercholesterolemic adults. J Nutr, 144(5), 599-607.

Fernandez-Arroyo, S., Camps, J., Menendez, J. A., \& Joven, J. (2015). Managing Hypertension by Polyphenols. Planta Medica, 81(8), 624-629.

Galleano, M., Pechanova, O., \& Fraga, C. G. (2010). Hypertension, Nitric Oxide, Oxidants, and Dietary Plant Polyphenols. Current Pharmaceutical Biotechnology, 11(8), 837-848.

García, M. C., Puchalska, P., Esteve, C., \& Marina, M. L. (2013). Vegetable foods: a cheap source of proteins and peptides with antihypertensive, antioxidant, and other less occurrence bioactivities. Talanta, 106, 328-349.

Guagagnucci Fontanari, G., Batistuti, J., da Cruz, R., Saldiva, P., \& Areas, J. (2012). Cholesterollowering effect of whole lupin (Lupinus albus) seed and its protein isolate. Food Chem, 132(3), 1521-1526.

Guang, C., \& Phillips, R. D. (2009). Plant Food-Derived Angiotensin I Converting Enzyme Inhibitory Peptides. J Agric Food Chem, 57(12), 5113-5120.

Hall, R., Thomas, S., \& Johnson, S. (2005). Australian sweet lupin flour addition reduces the glycaemic index of a white bread breakfast without affecting palatability in healthy human volunteers. Asia Pac J Clin Nutr, 14(1), 91-97.

Hall, R. S., Johnson, S. K., Baxter, A. L., \& Ball, M. J. (2005). Lupin kernel fibre-enriched foods beneficially modify serum lipids in men. Eur J Clin Nutr, 59(3), 325-333. 
Hamama, A. A., \& Bhardwaj, H. L. (2004). Phytosterols, triterpene alcohols, and phospholipids in seed oil from white lupin. J Am Oil Chem Soc, 81(11), 1039-1044.

Harland, J., \& Haffner, T. (2008). Systematic review, meta-analysis and regression of randomised controlled trials reporting an association between an intake of circa $25 \mathrm{~g}$ soya protein per day and blood cholesterol. Atherosclerosis, 200(1), 13-27.

Hodgson, J., Lee, Y., Puddey, I., Sipsas, S., Ackland, T., Beilin, L., Belski, R., \& Mori, T. (2010). Effects of increasing dietary protein and fibre intake with lupin on body weight and composition and blood lipids in overweight men and women. Int J Obes (Lond), DOI: 10.1038/ijo.2010.1026.

Huang, W. Y., Davidge, S. T., \& Wu, J. (2013). Bioactive natural constituents from food sourcespotential use in hypertension prevention and treatment. Crit Rev Food Sci Nutr, 53(6), 615630.

Huang, W. Y., Davidge, S. T., \& Wu, J. P. (2013). Bioactive Natural Constituents from Food Sources - Potential Use in Hypertension Prevention and Treatment. Critical Reviews in Food Science and Nutrition, 53(6), 615-630.

Hudson, B. J. F., Fleetwood, J. G., \& Lewis, J. I. (1983). Oil content, fatty acids and unsaponifiable lipids of lupin seed. Journal of Plant Foods, 5(1), 15-21.

Humiski, L. M., \& Aluko, R. E. (2007). Physicochemical and bitterness properties of enzymatic pea protein Hydrolysates. Journal of Food Science, 72(8), S605-S611.

Jenkins, D. J., Mirrahimi, A., Srichaikul, K., Berryman, C. E., Wang, L., Carleton, A., Abdulnour, S., Sievenpiper, J. L., Kendall, C. W., \& Kris-Etherton, P. M. (2010). Soy protein reduces serum cholesterol by both intrinsic and food displacement mechanisms. J Nutr, 140(12), 2302S-2311S.

Kamel, M. S. (2003). Flavone C-glycosides from Lupinus hartwegii. Phytochemistry, 63(4), 449452.

Katagiri, Y., Ibrahim, R. K., \& Tahara, S. (2000). HPLC analysis of white lupin isoflavonoids. Bioscience Biotechnology and Biochemistry, 64(6), 1118-1125. 
Keogh, J., Atkinson, F., Eisenhauer, B., Inamdar, A., \& Brand-Miller, J. (2011). Food intake, postprandial glucose, insulin and subjective satiety responses to three different bread-based test meals. Appetite, 57(3), 707-710.

Lammi, C., Zanoni, C., \& Arnoldi, A. (2015). Molecular characterization of the hypocholesterolemic mechanism of action of IAVPGEVA, IAVPTGVA, and LPYP, three peptides from soy glycinin, in HepG2 cells. Journal of Functional Foods, 14, 10.

Lammi, C., Zanoni, C., Scigliuolo, G. M., D'Amato, A., \& Arnoldi, A. (2014). Lupin peptides lower low-density lipoprotein (LDL) cholesterol through an up-regulation of the LDL receptor/sterol regulatory element binding protein 2 (SREBP2) pathway at HepG2 cell line. J Agric Food Chem, 62(29), 7151-7159.

Lee, Y. P., Mori, T. A., Puddey, I. B., Sipsas, S., Ackland, T. R., Beilin, L. J., \& Hodgson, J. M. (2009). Effects of lupin kernel flour-enriched bread on blood pressure: a controlled intervention study. Am. J. Clin. Nutr., 89(3), 766-772.

Lee, Y. P., Mori, T. A., Sipsas, S., Barden, A., Puddey, I. B., Burke, V., Hall, R. S., \& Hodgson, J. M. (2006). Lupin-enriched bread increases satiety and reduces energy intake acutely. Am J Clin Nutr, 84(5), 975-980.

Lovati, M. R., Manzoni, C., Castiglioni, S., Parolari, A., Magni, C., \& Duranti, M. (2012). Lupin seed $\gamma$-conglutin lowers blood glucose in hyperglycaemic rats and increases glucose consumption of HepG2 cells. Br J Nutr, 107(1), 67-73.

Lovati, M. R., Manzoni, C., Gianazza, E., Arnoldi, A., Kurowska, E., Carroll, K. K., \& Sirtori, C. R. (2000). Soy protein peptides regulate cholesterol homeostasis in Hep G2 cells. J Nutr, 130(10), 2543-2549.

Magni, C., Scarafoni, A., Herndl, A., Sessa, F., Prinsi, B., Espen, L., \& Duranti, M. (2007). Combined 2D electrophoretic approaches for the study of white lupin mature seed storage proteome. Phytochemistry, 68(7), 997-1007.

Magni, C., Sessa, F., Accardo, E., Vanoni, M., Morazzoni, P., Scarafoni, A., \& Duranti, M. (2004). Conglutin gamma, a lupin seed protein, binds insulin in vitro and reduces plasma glucose levels of hyperglycemic rats. J Nutr Biochem, 15(11), 646-650. 
Marchesi, M., Parolini, C., Diani, E., Rigamonti, E., Cornelli, L., Arnoldi, A., Sirtori, C. R., \& Chiesa, G. (2008). Hypolipidaemic and anti-atherosclerotic effects of lupin proteins in a rabbit model. British Journal of Nutrition, 100(4), 707-710.

Margatan, W., Ruud, K., Wang, Q., Markowski, T., \& Ismail, B. (2013). Angiotensin Converting Enzyme Inhibitory Activity of Soy Protein Subjected to Selective Hydrolysis and Thermal Processing. J. Agric. Food Chem., 61(14), 3460-3467.

Martins, J. M., Riottot, M., de Abreu, M. C., Viegas-Crespo, A. M., Lança, M. J., Almeida, J. A., Freire, J. B., \& Bento, O. P. (2005). Cholesterol-lowering effects of dietary blue lupin (Lupinus angustifolius L.) in intact and ileorectal anastomosed pigs. J Lipid Res, 46(7), 1539-1547.

Mellenthin, O., \& Galensa, R. (1999). Analysis of polyphenols using capillary zone electrophoresis and HPLC: Detection of soy, lupin, and pea protein in meat products. Journal of Agricultural and Food Chemistry, 47(2), 594-602.

Millan-Linares, M. d. C., Bermudez, B., Yust, M. d. M., Millan, F., \& Pedroche, J. (2014). Antiinflammatory activity of lupine ( Lupinus angustifolius L.) protein hydrolysates in THP-1derived macrophages. J Funct Foods, 8, 224-233.

Nowicka, G., Klosiewicz-Latoszek, L., Sirtori, C. R., Arnoldi, A., \& Naruszewicz, M. (2006). Lupin proteins in the treatment of hypercholesterolemia. Atherosclerosis, 7 (Suppl)(3), 477477.

Ogura, T., Ogihara, J., Sunairi, M., Takeishi, H., Aizawa, T., Olivos-Trujillo, M. R., MaureiraButler, I. J., \& Salvo-Garrido, H. E. (2014). Proteomic characterization of seeds from yellow lupin (Lupinus luteus L.). Proteomics, 14(12), 1543-1546.

Parolini, C., Rigamonti, E., Marchesi, M., Busnelli, M., Cinquanta, P., Manzini, S., Sirtori, C., \& Chiesa, G. (2012). Cholesterol-lowering effect of dietary Lupinus angustifolius proteins in adult rats through regulation of genes involved in cholesterol homeostasis. Food Chem, 132(3), 1475-1479.

Pilvi, T. K., Jauhiainen, T., Cheng, Z. J., Mervaala, E. M., Vapaatalo, H., \& Korpela, R. (2006). Lupin protein attenuates the development of hypertension and normalises the vascular function of NaCl-loaded Goto-Kakizaki rats. J. Physiol. Pharmacol., 57(2), 167-176. 
Puchalska, P., Marina Alegre, M. L., \& García López, M. C. (2015). Isolation and characterization of peptides with antihypertensive activity in foodstuffs. Crit Rev Food Sci Nutr, 55(4), 521551.

Radtke, J., Geissler, S., Schutkowski, A., Brandsch, C., Kluge, H., Duranti, M. M., Keller, S., Jahreis, G., Hirche, F., \& Stangl, G. I. (2014). Lupin protein isolate versus casein modifies cholesterol excretion and mRNA expression of intestinal sterol transporters in a pig model. Nutr Metab, 11(9), (3 February 2014).

Sato, S., Mukai, Y., Yamate, J., Kato, J., Kurasaki, M., Hatai, A., \& Sagai, M. (2008). Effect of polyphenol-containing azuki bean (vigna angularis) extract on blood pressure elevation and macrophage infiltration in the heart and kidney of spontaneously hypertensive rats. CLINICAL AND EXPERIMENTAL PHARMACOLOGY AND PHYSIOLOGY, 35(1), 43-49.

Schiarea, S., Arnoldi, L., Fanelli, R., De Combarieu, E., \& Chiabrando, C. (2013). In-depth glycoproteomic characterization of $\gamma$-conglutin by high-resolution accurate mass spectrometry. PLoS One, 8(9), e73906.

Scicchitano, P., Cameli, M., Maiello, M., Modesti, P. A., Muiesan, M. L., Novo, S., Palmiero, P., Saba, P. S., Pedrinelli, R., Ciccone, M. M., \& Soc Italiana, C. (2014). Nutraceuticals and dyslipidaemia: Beyond the common therapeutics. Journal of Functional Foods, 6, 11-32.

Shahidi, F., \& Chandrasekara, A. (2013). Millet grain phenolics and their role in disease risk reduction and health promotion: A review. Journal of Functional Foods, 5(2), 570-581.

Siger, A., Czubinski, J., Kachlicki, P., Dwiecki, K., Lampart-Szczapa, E., \& Nogala-Kalucka, M. (2012). Antioxidant activity and phenolic content in three lupin species. Journal of Food Composition and Analysis, 25(2), 190-197.

Sirtori, C. R., Eberini, I., \& Arnoldi, A. (2007). Hypocholesterolaemic effects of soya proteins: results of recent studies are predictable from the anderson meta-analysis data. $\mathrm{Br} J \mathrm{Nutr}$, 97(5), 816-822.

Sirtori, C. R., Lovati, M. R., Manzoni, C., Castiglioni, S., Duranti, M., Magni, C., Morandi, S., D'Agostina, A., \& Arnoldi, A. (2004). Proteins of white lupin seed, a naturally isoflavonepoor legume, reduce cholesterolemia in rats and increase LDL receptor activity in HepG2 cells. J Nutr, 134(1), 18-23. 
Sirtori, C. R., Triolo, M., Bosisio, R., Bondioli, A., Calabresi, L., De Vergori, V., Gomaraschi, M., Mombelli, G., Pazzucconi, F., Zacherl, C., \& Arnoldi, A. (2012). Hypocholesterolaemic effects of lupin protein and pea protein/fibre combinations in moderately hypercholesterolaemic individuals. Brit J Nutr, 107(8), 1176-1183.

Sirtori, E., Resta, D., Brambilla, F., Zacherl, C., \& Arnoldi, A. (2010). The effects of various processing conditions on a protein isolate from Lupinus angustifolius. Food Chem, 120(2), 496-504.

Song, C. W., Huang, L., Rong, L., Zhou, Z. W., Peng, X. H., Yu, S. G., \& Fang, N. A. B. (2012). Anti-hyperglycemic effect of Potentilla discolor decoction on obese-diabetic $(\mathrm{Ob}-\mathrm{db})$ mice and its chemical composition. Fitoterapia, 83(8), 1474-1483.

Stalmach, A., Mullen, W., Pecorari, M., Serafini, M., \& Crozier, A. (2009). Bioavailability of CLinked Dihydrochalcone and Flavanone Glucosides in Humans Following Ingestion of Unfermented and Fermented Rooibos Teas. Journal of Agricultural and Food Chemistry, 57(15), 7104-7111.

Sujak, A., Kotlarz, A., \& Strobel, W. (2006). Compositional and nutritional evaluation of several lupin seeds. Food Chem, 98(4), 711-719.

Taku, K., Umegaki, K., Sato, Y., Taki, Y., Endoh, K., \& Watanabe, S. (2007). Soy isoflavones lower serum total and LDL cholesterol in humans: a meta-analysis of 11 randomized controlled trials. American Journal of Clinical Nutrition, 85(4), 1148-1156.

Terruzzi, I., Senesi, P., Magni, C., Montesano, A., Scarafoni, A., Luzi, L., \& Duranti, M. (2011). Insulin-mimetic action of conglutin-gamma, a lupin seed protein, in mouse myoblasts. Nutrition Metabolism and Cardiovascular Diseases, 21(3), 197-205.

Tomatsu, M., Shimakage, A., Shinbo, M., Yamada, S., \& Takahashi, S. (2013). Novel angiotensin I-converting enzyme inhibitory peptides derived from soya milk. Food Chemistry, 136(2), 612-616.

Vargas-Guerrero, B., Garcia-Lopez, P. M., Martinez-Ayala, A. L., Dominguez-Rosales, J. A., \& Gurrola-Diaz, C. M. (2014). Administration of Lupinus albus Gamma Conglutin (C gamma) to 5 STZ Rats Augmented Ins-1 Gene Expression and Pancreatic Insulin Content. Plant Foods Hum Nutr, 69(3), 241-247. 
Wait, R., Gianazza, E., Brambilla, D., Eberini, I., Morandi, S., Arnoldi, A., \& Sirtori, C. R. (2005). Analysis of Lupinus albus storage proteins by two-dimensional electrophoresis and mass spectrometry. J Agric Food Chem, 53(11), 4599-4606.

Wang, S., Errington, S., Yap, H., Wang, S. F., \& Yap, H. H. (2008). Studies on carotenoids from lupin seeds. Lupins for health and wealth. Proceedings of the 12th International Lupin Conference, Fremantle, Western Australia, 14-18 September 2008, 198-202.

Weisse, K., Brandsch, C., Zernsdorf, B., Nkengfack Nembongwe, G. S., Hofmann, K., Eder, K., \& Stangl, G. I. (2010). Lupin protein compared to casein lowers the LDL cholesterol:HDL cholesterol-ratio of hypercholesterolemic adults. Eur J Nutr, 49(2), 65-71.

Wu, J., \& Ding, X. (2002). Characterization of inhibition and stability of soy-protein-derived angiotensin I-converting enzyme inhibitory peptides. Food Res. Int., 35, 367-375. 
Figure 1. Structures of the main polyphenols in lupin seed. 